\title{
Analisis Following to Likes Ratio TikTok Pada 10 Akun TikTok Terkaya di Dunia
}

\author{
I Made Krishna Aditya
}

krishnaaditya924@gmail.com

\begin{abstract}
The TikTok application is a social media network that is used by its users to create short videos with a maximum duration of 60 seconds. This application was launched by a Chinese company, ByteDance. TikTok's active users as of July 2020 have reached 689.17 million users and more than 2 billion have been downloaded globally. The presence of TikTok social media can also build the owner's personal branding. The TikTok fever in the world has made some influencers rich from the video social media application. The Top 10 influencers who have accumulated wealth from playing TikTok and are listed as the richest TikTokers in the world include: Spancer X, Michael Le, Josh Richards, Riyaz Aly, Loren Grey, Dixie D'Amelio, Zach King, Charli D'Amelio, Addison Rae Easterling, and Baby Ariel. The purpose of this study is to determine the credibility value of the performance of the 10 richest TikTok accounts in the world in Q2-2021. The method used for this research is quantitative exploratory method. The results of this study indicate that Riyaz Aly's TikTok account has better credibility than other TikTok accounts.
\end{abstract}

\begin{abstract}
ABSTRAK
Aplikasi TikTok merupakan jaringan media sosial yang digunakan oleh penggunanya untuk membuat video pendek dengan durasi maksimal 60 detik. Aplikasi ini diluncurkan oleh perusahaan asal Tiongkok yaitu ByteDance. Pengguna aktif TikTok hingga Juli 2020 sudah mencapai 689,17 juta user dan sudah diunduh 2 miliar lebih secara global. Kehadiran media sosial TikTok juga dapat membangun personal branding pemiliknya. Demam TikTok di dunia telah membuat sebagian influencer menjadi kaya dari aplikasi media sosial video tersebut. Adapun Top 10 influencer yang berhasil mengumpulkan kekayaan dari bermain TikTok dan tercatat menjadi TikToker terkaya di Dunia, diantaranya yaitu: Spancer X, Michael Le, Josh Richards, Riyaz Aly, Loren Grey, Dixie D'Amelio, Zach King, Charli D'Amelio, Addison Rae Easterling, dan Baby Ariel. Tujuan dari penelitian ini adalah untuk mengetahui nilai kredibilitas dari performa 10 akun TikTok terkaya di Dunia pada tahun Q2-2021. Metode yang digunakan untuk penelitian ini yaitu metode eksploratif kuantitatif. Hasil penelitian ini menunjukan bahwa akun TikTok Riyaz Aly memiliki kredibilitas performa yang lebih baik dibandingkan dengan akun TikTok yang lainnya.
\end{abstract}

Keyword: Credibility Account TikTok; Social Media TikTok; Following to Likes Ratio; Richest TikTok influencer. 


\section{PENDAHULUAN}

Pesatnya perkembangan teknologi informasi dan komunikasi di jaman sekarang memungkinkan masyarakat untuk berkomunikasi dan berinteraksi dengan cara yang berbeda melalui media sosial. Manfaat yang diberikan oleh media sosial membuat masyarakat menggunakan media sosial sebagai sarana berkomunikasi dalam kehidupan sehari-hari. Komunikasi yang dilakukan menggunakan berbagai macam aplikasi media sosial seperti Facebook, Twitter, Line, Whatsapp, Instagram, Youtube dan beberapa aplikasi lainnya yang dapat mempermudah masyarakat dalam berkomunikasi dan berinteraksi.

Dengan pesatnya perkembangan teknologi media sosial, muncul banyak platform aplikasi media sosial yang menyediakan fasilitas dan fitur-fitur y ang berbeda-beda. Contohnya aplikasi sosial media yang sedang populer di kalangan remaja saat ini yaitu TikTok. Aplikasi TikTok merupakan jaringan media sosial yang digunakan oleh penggunanya untuk membuat video pendek dengan durasi maksimal 60 detik (Dewanta 2020). Aplikasi ini diluncurkan oleh perusahaan asal Tiongkok yaitu ByteDance.

Kehadiran media sosial TikTok juga dapat membangun personal branding pemiliknya (Ishihara and Oktavianti 2021). Dilaporkan bahwa pengguna aktif Tiktok hingga Juli 2020 sudah mencapai 689,17 juta user dan sudah diunduh 2 miliar lebih secara global ("Berapa Pengguna Aktif TikTok Di Dunia? Jangan Kaget Yah!” n.d.). Demam TikTok di dunia telah membuat sebagian influencer menjadi kaya dari aplikasi media sosial video tersebut. Adapun Top 10 influencer yang berhasil mengumpulkan kekayaan dari bermain TikTok dan terca tat menjadi TikToker terkaya di Dunia, diantaranya yaitu: Spancer X, Michael Le, Josh Richards, Riyaz Aly, Loren Grey, Dixie D'Amelio, Zach King, Charli D'Amelio, Addison Rae Easterling, dan Baby Ariel (“10 Tiktoker Terkaya Di Dunia - Lifestyle Bisnis.Com” n.d.).

Penelitian ini menggunakan metode eksploratif kuantitatif, dan akan menghitung menggunakan rasio-rasio yang ada pada TikTok. Pada penelitian (Permana and Meinarni 2021) menjelaskan bahwa terdapat 17 rasio yang ada pada sosial media TikTok dan relevan digunakan sebagai media ukur kredibilitas akun yang ada. Penelitian ini hanya berfokus untuk menghitung kredibilitas Following to Likes Ratio pada 10 akun Tiktok terkaya di Dunia, diantaranya yaitu : Spancer X, Michael Le, Josh Richards, Riyaz Aly, Loren Grey, Dixie D'Amelio, Zach King, Charli D'Amelio, Addison Rae Easterling, dan Baby Ariel ("10 Tiktoker Terkaya Di Dunia - Lifestyle Bisnis.Com” n.d.). Tujuan dari penelitian ini adalah mengetahui kredibilitas performa dari 10 akun TikTok terkaya di Dunia menggunakan Following to Likes Ratio.

\section{TINJAUAN PUSAKA}

Perkembangan teknologi informasi dan komunikasi saat ini tidak akan terlepas dengan adanya perkembangan teknologi. Alat komunikasi yang tercipta dengan adanya perkembangan teknologi, salah satu contohnya adalah smartphone baik yang berbasis operating system android, windows mobile hingga IOS semuanya terhubung atau terkoneksi dengan internet (Setiadi 2014). Dengan berkembangnya smartphone dan banyak masyarakat menggunakannya 
sebagai alat komunikasi dan mencari informasi dalam kehidupan sehari-hari menimbulkan banyak platform aplikasi-aplikasi komunikasi seperti media sosial yang bermunculan, seperti Facebook, Twitter, Line, Whatsapp, Instagram, Youtube, TikTok dan beberapa aplikasi lainnya.

Media sosial merupakan sebuah medium di internet yang memungkinkan penggunanya untuk merepresentasikan diri dan melakukan interaksi, bekerjasama, berbagi, komunikasi dengan pengguna lain dan membentuk ikatan sosial secara virtual (Puspitarini and Nuraeni 2019). Awalnya komunikasi dalam media sosial berjalan hanya searah, dalam arti penikmat media hanya bisa menikmati konten yang disajikan sumber media. Namun seiring perkembangan jaman, masyarakat sebagai pengguna media tidak lagi hanya bisa menikmati konten dari media yang terpapar padanya, namun sudah bisa ikut serta mengisi konten di media tersebut (Watie 2016).

TikTok merupakan aplikasi yang sangat populer di lingkungan masyarakat. Aplikasi TikTok merupakan jaringan media sosial yang digunakan oleh penggunanya untuk membuat video pendek dengan durasi maksimal 60 detik (Dewanta 2020). Pengguna dapat membagikan kreativitasnya dalam membuat video pendek yang menarik ke aplikasi TikTok sehingga dapat dilihat dan dikenal oleh banyak orang. Aplikasi TikTok tercatat menjadi aplikasi paling populer kedua setelah WhatsApp dengan jumlah unduhan sekitar 220 juta, mengungguli Facebook dan Instagram sebagai aplikasi non gim (Saputra, Dhuatu, and Giyato 2020). Aplikasi TikTok dapat membangun personal branding pemiliknya (Ishihara and Oktavianti 2021). Oleh karena itu, TikTok juga dapat memberikan peluang untuk para akun kreator yang sudah cukup terkenal dalam mendapatkan penghasilan dengan mempromosikan produknya sendiri atau dari pihak lain kepada penontonnya.

Dengan banyaknya pengguna TikTok yang ada, membuat aplikasi ini memiliki pengaruh yang cukup besar dalam digital marketing, Kredibilitas akun TikTok merupakan suatu hal yang cukup penting untuk berbagai kepentingan. Kredibilitas sebuah akun TikTok dapat diukur dari tingkat performa yang dihasilkan secara matematis. Dalam mengukur performa diperlukan skala pengukuran yang tertuang ke dalam rasio (Permana and Meinarni 2021).

\section{METODE PENELITIAN}

Penelitian ini menggunakan metode eksploratif kuantitatif untuk mengetahui kredibilitas dari performa 10 akun TikTok terkaya di Dunia pada tahun 2021. Metode eksploratif adalah penelitian yang bertujuan mencari dan merumuskan masalah-masalah dari suatu fenomena (Mudjiyanto 2018).

Tujuan dari penelitian ini adalah untuk mengetahui nilai kredibilitas dari performa 10 akun TikTok terkaya di Dunia pada tahun 2021. Dalam penelitian ini, ada beberapa langkah yang harus dilakukan untuk dapat menentukan peringkat pertama akun TikTok terkaya di Dunia yang memiliki performa terbaik. Langkah-langkah tersebut, yaitu:

1) Melakukan Eksplorasi Pada Website Untuk Menentukan Objek yang Akan Dianalisa. 
Eksplorasi dilakukan pada beberapa website yang menyediakan informasi tentang objek yang akan di teliti. Ketika eksplorasi selesai, nama-nama akun yang ditemukan akan dijadikan objek analisa. Langkah selanjutnya yaitu mencari nama akun-akun tersebut di aplikasi TikTok. Pastikan semua akun terdaftar pada aplikasi sosial media TikTok.

\section{2) Menghitung Nilai Variable Dari 10 akun TikTok terkaya di Dunia.}

Dalam langkah ini, peneliti menghitung nilai variable following dan variable likes dari masing-masing akun. Variabel adalah sasaran-sasaran penelitian yang mempunyai variasi nilai (Nasution 2017). Untuk mendapatkan nilai dari variable following dan variable likes, peneliti menghitung total likes dan total following yang dimiliki oleh setiap akun sehingga menemukan nilai dari masing-masing variabel tersebut.

\section{3) Menghitung Nilai Kredibilitas Rasio.}

Hal yang dalam menghitung nilai kredibilitas dari following to likes ratio dari masingmasing akun yaitu dengan membagi nilai variabel following dengan nilai variabel likes. Jika variable following memiliki nilai 200 dan variable likes memiliki nilai 100000, maka cara menghitungnya yaitu $200: 100000=0,002$. Dengan begitu nilai dari following to likes ratio adalah 0,002 .

\section{4) Menentukan Peringkat Pada Akun TikTok}

Pada langkah terakhirini, dilakukan penentuan peringkat pada masing-masing rasio yang ada. Dalam menentukan peringkat, karakteristik dari rasio yang di teliti harus dipertimbangkan terlebih dahulu. Terdapat dua karakteristik rasio yaitu rasio rendah dan tinggi. Jika karakteristik rasio rendah, maka objek yang memiliki nilai terendah akan mendapatkan angka 10 dan objek yang memiliki nilai tertinggi akan mendapatkan angka 1. Sedangkan jika karakteristik rasio tinggi maka objek yang mendapatkan nilai tinggi akan mendapatkan angka 10 dan objek yang mendapatkan nilai terendah akan mendapatkan angka 1. Setelah mendapatkan hasil kredibilitas ratio dari masing-masing objek, maka dapat disimpulkan objek yang mana mendapatkan peringkat 1 sampai dengan peringkat 10 . 


\section{HASIL DAN PEMBAHASAN}

Akun TikTok dari 10 Akun Terkaya di Dunia Q2-2021, diantaranya:

\section{Spencer $\mathbf{X}$}

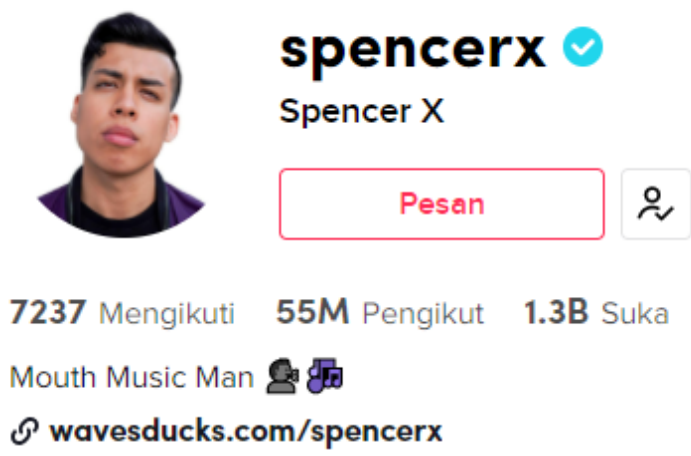

Gambar 1. Akun TikTok Spencer X

Sumber: https://www.tiktok.com/@spencerx (akses pada 21-10-2021)

\section{Michael Le}

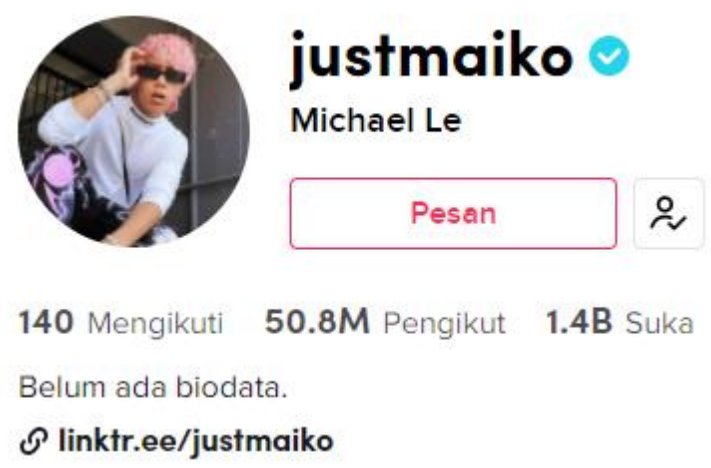

Gambar 2. Akun TikTok MichaelLe

Sumber: https://www.tiktok.com/@justmaiko (akses pada 21-10-2021)

\section{Josh Richards}

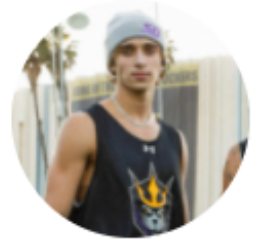

\section{joshrichards}

\section{Josh Richards}

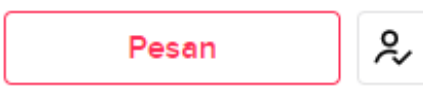

$$
9498 \text { Mengikuti 25.6M Pengikut 1.7B Suka }
$$

Tap link below for podcast, merch \& more! $\square$

$\mathcal{O}$ linktr.ee/joshrichards

Ga mbar 3. Akun TikTok Josh Richards

Sumber: https://www.tiktok.com/@joshrichards (akses pada 21-10-2021) 
4. Riyaz Aly

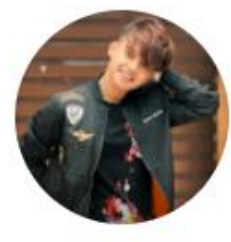

\section{riyaz.14}

Riyaz

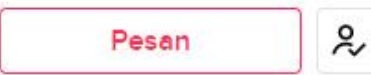

43 Mengikuti 44.4M Pengikut 2.1B Suka

Actor

Instagram: @riyaz.14 \&

Use \#DuetWithRiyaz for duets 8

Gambar4. Akun TikTok Riyaz Aly

Sumber: https://www.tiktok.com/@riyaz.14 (akses pada 21-10-2021)

\section{Loren Gray}

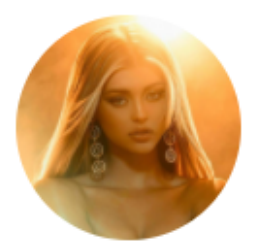

\section{lorengray}

Loren Gray

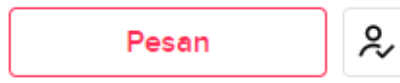

235 Mengikuti 54.1M Pengikut 2.9B Suka

piece of work out now $<3$

$\mathcal{N}$ withkoji.com/@lorengray

Gambar 5. Akun TikTok Loren Gray

Sumber: https://www.tiktok.com/@lorengray (akses pada 21-10-2021)

\section{Dixie D'Amelio}

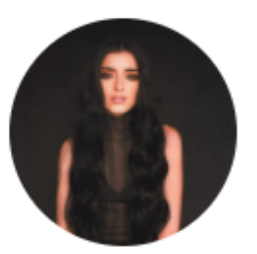

\section{dixiedamelio}

dixie

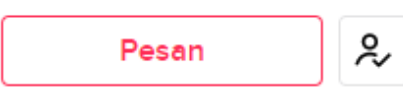

1553 Mengikuti

55.3M Pengikut

3.1B Suka

thanks for watching

$\mathcal{O}$ hitco.Ink.to/therealthing

Gambar 6. Akun TikTok Dixie D'Amelio

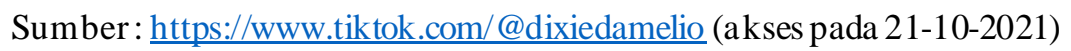


7. Zach King

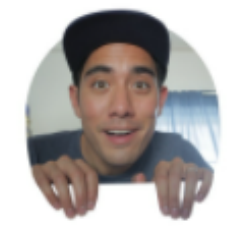

\section{zachking}

Zach King

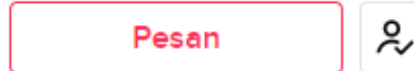

47 Mengikuti 65.9M Pengikut 819.9M Suka

Bringing a little more wonder into the world, 15 seconds at a time

$\mathcal{N}$ www.zachkingteam.com/links

Gambar 7. Akun TikTokZach King

Sumber: https://www.tiktok.com/@zachking (akses pada 21-10-2021)

\section{Charli D'Amelio}

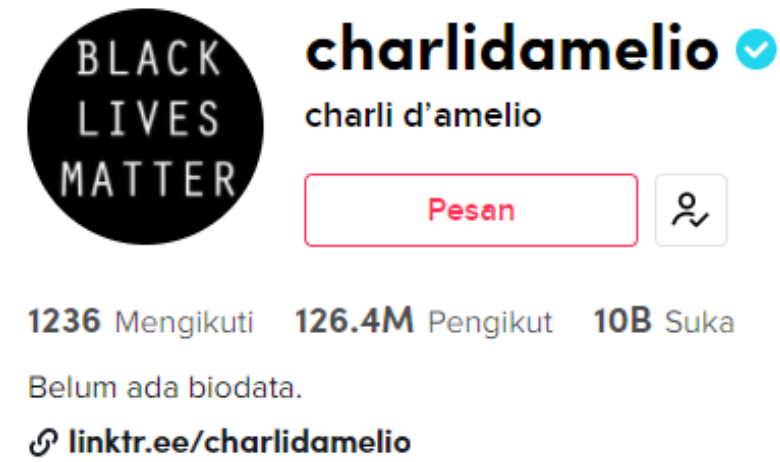

Gambar 8. Akun TikTok Charli D'Amelio

Sumber: https://www.tiktok.com/@ charlidamelio (akses pada 21-10-2021)

9. Addison Rae Easterling

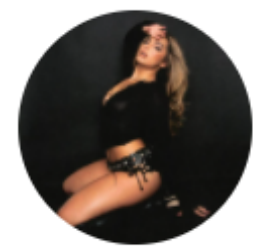

\section{addisonre} Addison Rae

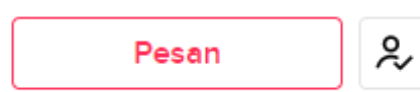

2442 Mengikuti 85.1M Pengikut 5.5B Suka

OBSESSED out on all platforms.

$\mathcal{O}$ netflix.com/title/81446038

Gambar9. Akun TikTok Addison RaeEa sterling

Sumber: https://www.tiktok.com/@addisonre (akses pada 21-10-2021) 
10. Baby Ariel

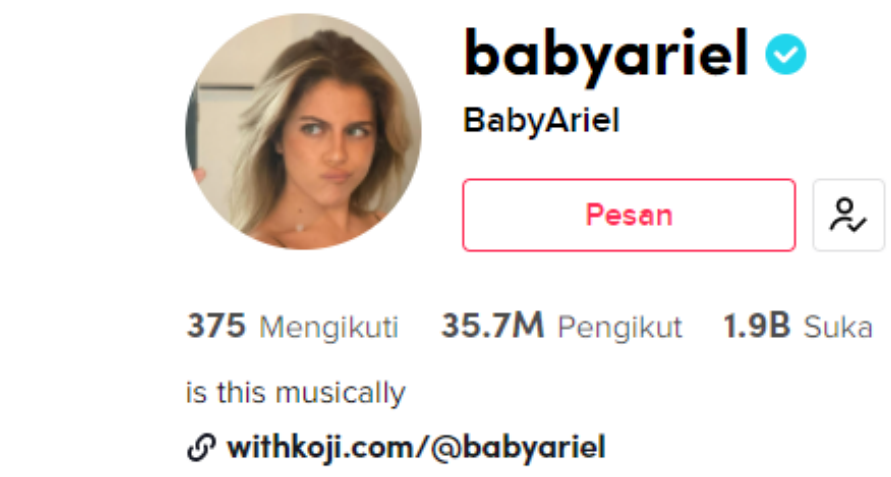

Ga mbar 10. Akun TikTok Baby Ariel

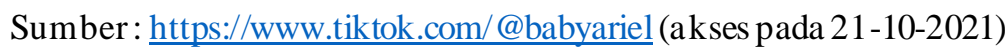

Dari sepuluh akun TikTok Terkaya di Dunia Q2-2021, peneliti menemukan nilai dari masingmasing variabel yang ada untuk menghitung rasio Following to Likes dari setiap akun. Pada akun TikTok terdapat 7 variabel, diantaranya yaitu :

1. Likes

2. Followers

3. Following

4. Video Likes

5. Video Comments

6. Video Share

7. Video Views

Dari ketujuh variabel tersebut peneliti hanya fokus untuk menemukan hasil dari 2 variabel, yaitu :

1. Following

2. Likes

Dari kedua variabel tersebut kemudian dianalisa sehingga menemukan nilai dari variabel Following dan variabel Likes. Untuk menghitung nilai dari variabel following dan variabel likes yaitu dengan cara mengambil total following dan likes pada setiap akun sehingga menemukan nilai dari masing-masing variabel. Berikut merupakan hasil akhir dari nilai variabel following dan likes :

Tabel 1. Nilai VariabelPa da 10 Akun TikTok Terkaya di Dunia Q2-2021

\begin{tabular}{|c|c|c|c|}
\hline No & Variable & Following & Likes \\
\hline 1 & Spancer X & 7.212 & 1.300 .000 .000 \\
\hline 2 & Michael Le & 134 & 1.400 .000 .000 \\
\hline 3 & Josh Richards & 9.498 & 1.700 .000 .000 \\
\hline 4 & Riyaz Aly & 43 & 2.100 .000 .000 \\
\hline 5 & Loren Grey & 235 & 2.900 .000 .000 \\
\hline
\end{tabular}




\begin{tabular}{|c|c|c|c|}
6 & Dixie D'Amelio & 1.539 & 3.100 .000 .000 \\
\hline 7 & Zach King & 47 & 814.000 .000 \\
\hline 8 & Charli D'Amelio & 1.234 & 9.900 .000 .000 \\
\hline 9 & $\begin{array}{c}\text { Addison Rae } \\
\text { Easterling }\end{array}$ & 2.436 & 5.400 .000 .000 \\
\hline 10 & Baby Ariel & 372 & 1.900 .000 .000 \\
\hline
\end{tabular}

Sumber: Pengolah Data Excel

Pada akun TikTok terdapat 17 rasio y ang relevan digunakan untuk mengukur kredibilitas pada masing-masing akun. Namun pada penelitian kali ini hanya berfokus untuk menghitung Following to Likes Ratio. Untuk menghitung kredibilitas dari masing-masing akun TikTok, peneliti menghitung dengan cara, variabel 1 akan dibagi dengan variabel 2, sehingga ditemukan hasil analisis dari rasio tersebut.

Tabel 2. HasilPerhitungan Rasio 10 Akun TikTok Terkaya di Dunia Q2-2021

\begin{tabular}{|c|c|c|}
\hline No & RATIO & Following to Likes Ratio \\
\hline 1 & Spancer X & 0,00000555 \\
\hline 2 & Michael Le & 0,0000001 \\
\hline 3 & Josh Richards & 0,00000559 \\
\hline 4 & Riyaz Aly & 0,00000002 \\
\hline 5 & Loren Grey & 0,00000008 \\
\hline 6 & Dixie D'Amelio & 0,0000005 \\
\hline 7 & Zach King & 0,00000006 \\
\hline 8 & Charli D'Amelio & 0,00000012 \\
\hline 9 & $\begin{array}{c}\text { Addison Rae } \\
\text { Easterling }\end{array}$ & 0,00000045 \\
\hline 10 & Baby Ariel & 0,0000002 \\
\hline
\end{tabular}

Sumber: Pengolah Data Excel

Following to Likes Ratio memiliki karakteristik yang rendah, artinya semakin rendah nilai yang dihasilkan maka semakin baik kredibilitas dari performa akun tersebut. Untuk memberikan peringkat pada masing-masing akun TikTok, peneliti memberikan angka 10 kepada akun Tiktok yang mendapatkan nilai rendah dan angka 1 untuk akun yang mendapatkan nilai tertinggi. Berikut merupakan tabel urutan nilai yang dihasilkan oleh masing-masing akun TikTok.

Tabel 3. Nilai Ra sio 10 Akun TikTok Terkaya di Dunia Q2-2021

\begin{tabular}{|c|c|c|}
\hline No & Ratio & Following to Likes Ratio \\
\hline 1 & Spancer X & 2 \\
\hline 2 & Michael Le & 7 \\
\hline 3 & Josh Richards & 1 \\
\hline
\end{tabular}




\begin{tabular}{|c|c|c|}
4 & Riyaz Aly & 10 \\
\hline 5 & Loren Grey & 8 \\
\hline 6 & Dixie D'Amelio & 3 \\
\hline 7 & Zach King & 9 \\
\hline 8 & Charli D'Amelio & 6 \\
\hline 9 & $\begin{array}{c}\text { Addison Rae } \\
\text { Easterling }\end{array}$ \\
\hline 10 & Baby Ariel & 4 \\
\hline
\end{tabular}

Sumber: Pengolah Data Excel

Dari Tabel Nilai Rasio 10 Akun TikTok Terkaya di Dunia Q2-2021 dapat disimpulkan bahwa akun TikTok Riyaz Aly mendapatkan nilai tertinggi untuk rasio Following to Likes. Sedangkan akun TikTok Josh Richards mendapatkan nilai terendah untuk rasio ini. Jadi, pada penelitian ini akun TikTok Riyaz Aly memiliki kredibilitas performa yang lebih baik dibandingkan dengan akun TikTok yang lainnya

\section{Kesimpulan}

Tujuan dari penelitian ini adalah mengetahui kredibilitas performa dari 10 Akun TikTok Terkaya di Dunia menggunakan Following to Likes Ratio. 10 Akun TikTok tersebut diantaranya: Spancer X, Michael Le, Josh Richards, Riyaz Aly, Loren Grey, Dixie D'Amelio, Zach King, Charli D'Amelio, Addison Rae Easterling, dan Baby Ariel. Dari sepuluh akun TikTok tersebut dapat disimpulkan bahwa:

1. Peringkat pertama diraih oleh Riyaz Aly dengan nilai terendah yaitu 0,00000002

2. Peringkat kedua diraih oleh Zach King dengan nilai 0,00000006

3. Peringkat ketiga diraih oleh Loren Grey dengan nilai 0,00000008

4. Peringkat keempat diraih oleh Michael Le dengan nilai 0,00000010

5. Peringkat kelima diraih oleh Charli D'Amelio dengan nilai 0,00000012

6. Peringkat keenam diraih oleh Baby Ariel dengan nilai 0,00000020

7. Peringkat ketujuh diraih oleh Addison Rae Easterling dengan nilai 0,00000045

8. Peringkat kedelapan diraih oleh Dixie D'Amelio dengan nilai 0,00000050

9. Peringkat kesembilan diraih oleh Spancer X dengan nilai 0,00000555

10. Peringkat kesepuluh diraih oleh Josh Richards dengan nilai tertinggi yaitu 0,00000559 


\section{DAFTAR PUSTAKA}

“10 Tiktoker Terkaya Di Dunia - Lifestyle Bisnis.Com.”n.d. Accessed October 27, 2021. https://lifestyle.bisnis.com/read/20210520/220/1396097/10-tiktoker-terkaya-di-dunia.

"Berapa Pengguna Aktif TikTok Di Dunia? Jangan Kaget Yah!” n.d. Accessed October 28, 2021. https://www.cnbcindonesia.com/tech/20200825104121-37-181742/berapapengguna-aktif-tiktok-di-dunia-jangan-kaget-yah.

Dewanta, Anak Agung Ngurah Bagus Janitra. 2020. "Pemanfaatan Aplikasi Tik Tok Sebagai Media Pembelajaran Bahasa Indonesia." Jurnal Pendidikan Dan Pembelajaran Bahasa Indonesia 8 (2): 95-102.

Ishihara, Yemikaori Yumna Ulya, and Roswita Oktavianti. 2021. "Personal Branding Influencer Di Media Sosial TikTok.” Koneksi 5 (1): 76-82. https://doi.org/10.24912/KN.V5I1.10162.

Mudjiyanto, Bambang. 2018. “Tipe Penelitian Eksploratif Komunikasi.” Jurnal Studi Komunikasi Dan Media 22 (1): 65. https://doi.org/10.31445/jskm.2018.220105.

Nasution, Sangkot. 2017. "Variabel Penelitian." Raudhah 05 (02): 1-9. http://jurnaltarbiyah.uinsu.ac.id/index.php/raudhah/article/view/182.

Permana, I Putu Hendika, and Ni Putu Suci Meinarni. 2021. "Ratio Analysis on Tiktok (Social Media) for Qualitative Research Using Explorative Methods.” Jurnal Ekonomi \& Bisnis JAGADITHA 8 (1): 30-38. https://doi.org/10.22225/JJ.8.1.2944.30-38.

Puspitarini, Dinda Sekar, and Reni Nuraeni. 2019. "Pemanfaatan Media Sosial Sebagai Media Promosi (Studi Deskriptif Pada Happy Go Lucky House).” Jurnal Common 3 (1): 71-80. https://ojs.unikom.ac.id/index.php/common/article/view/1950.

Saputra, Vicky Rian, Chantiq Hast Dhuatu, and Giyato Giyato. 2020. "Pemanfaatan Aplikasi Tiktok Sebagai Mood Booster (the Usage of Tiktok App To Increase Mood Level).” Indonesian Fun Science Award 2 (1): 216-26. https://proceedings.sgu.ac.id/if sj/index.php/if sj/article/view/53.

Setiadi, Ahmad. 2014. "Pemanfaatan Media Sosial Untuk Efektifitas Komunikasi." Jurnal Ilmiah Matrik 16 (1).

Watie, Errika Dwi Setya. 2016. "Komunikasi Dan Media Sosial (Communications and Social Media)." Jurnal The Messenger 3 (2): 69. https://doi.org/10.26623/themessenger.v3i2.270. 